\title{
Pseudomonas aeruginosa productora de metabolito con actividad antimicrobiana contra Burkholderia glumae
}

\section{Pseudomonas aeruginosa producer of metabolite with antimicrobial activity against Burkholderia glumae}

\author{
Barraza R, Zafiro M.Sc, Bravo J, Ana Biol., Pérez-Cordero, Alexander Ph.D. \\ ${ }^{1}$ Universidad de Sucre, Laboratorio de Investigaciones Microbiológica. Sincelejo, Colombia. \\ ${ }^{2}$ Universidad de Sucre, Facultad de Ciencias Agropecuarias, Grupo de investigación en \\ Bioprospección Agropecuaria. Sincelejo, Colombia.
}

\section{Keywords:}

Bacterial compounds; endophytes bacteria; biocontrol phytopathogen.

\section{Abstract}

The present study had as objective to evaluate in vitro antimicrobial activity of endphytes bacteria associated with Neem (Azadirachta indica) against Burkholderia glumae. The inhibitory activity of endophytic bacteria against $B$. glumae was evaluated by antagonism, using the technique of diffusion in agar with sensitive records. Once identified the endophytic bacteria inhibitory potential, used discs medium numbers 3 for production of secondary metabolites, to test their inhibition against $B$. glumae by Elisa plate microdilution methods. The results showed an inhibition of $50 \%$ of the growth against $B$. glumae, the identification with API 20 NE kit found in $99,55 \%$ to the species Pseudomonas aeruginosa.

\section{Palabras Clave:}

Compuestos bacterianos; bacterias endófitas: biocontrol de fitopatogenos.
INFORMACIÓN Recibido: 05-10-2016; Aceptado: 22-03-2017. Correspondencia autor: alexpcor@yahoo.com

\section{Resumen}

El presente estudio tuvo como objetivo evaluar in vitro la actividad antimicrobiana de bacterias endófitas asociadas a Neem (Azadirachta indica) contra la bacteria fitopatógena Burkholderia glumae. La actividad inhibitoria de bacterias endófitas contra $B$. glumae se evaluó por antagonismo, mediante la técnica de difusión en agar con discos sensitivos. Una vez identificadas las bacterias endófitas con potencial inhibitorio, se empleó medio número 3 para producción de metabolitos secundarios, para probar su inhibición contra $B$. glumae mediante la técnica de microdilucion en placas de Elisa. Los resultados mostraron, una inhibición del $50 \%$ del crecimiento de B. glumae por parte de la bacteria endófita asilada. La identificación de la bacteria endófita con potencial inhibitorio contra $B$. glumae se realizó por medio un kit API 20 NE, donde el perfil de identificación arrojo un 99,5\% para Pseudomonas aeruginosa. 


\section{INTRODUCCIÓN}

El arroz es uno de los cultivos más importantes del mundo, donde su producción ha jugado un papel trascendental en el desarrollo económico en muchos países, además por ser un alimento básico en la dieta alimentaria de más de la mitad de la población mundial, ya que aporta un gran valor calorífico y valor nutricional. En Colombia el arroz representa uno de los cultivos de mayor interés económico siendo el tercer país productor de América Latina y del Caribe después de Brasil y Perú (FAO, 2010) y a nivel mundial ocupa el puesto 22 con una producción anual de 0,4\% (ESPINAL, 2005). Sin embargo, aunque tenga una extensa área cultiva de arroz, los valores de rendimiento del cultivo disminuyen drásticamente en términos de cosecha. Una de las principales limitaciones del cultivo de arroz en Colombia es a causa de enfermedades bacterianas, fúngicas, víricas o plagas que tienen un impacto negativo en la producción y rendimiento del cultivo. Dentro de estas enfermedades se encuentra el añublo bacteriano de la panícula del arroz, causada por B. glumae, la cual ha aumentado su incidencia en los últimos años provocando pérdidas hasta de un $40 \%$ en la producción (IWAI et al., 2002; RUSH et al., 2003). Los síntomas de la enfermedad se pueden presentar en las plántulas, en la vaina de la hoja y en las espiguillas de las panículas. Las panículas afectadas registran espiguillas de color pajizo, decoloración del grano y pudrición. La bacteria se multiplica rápidamente y los síntomas aparecen desde la emergencia de la panícula.

Además, esta especie es causante del marchitamiento en muchos cultivos de campo como tomate, chile, berenjena, papa, girasol (UEMATSY et al., 1976). La problemática de dichos cultivos y el gran aumento de la resistencia de los microorganismos a pesticidas sintéticos utilizados convencionalmente, los países ricos en biodiversidad deben asumir el gran reto de vincular y utilizar las sustancias provenientes de los recursos biológicos en compuestos, procesos, herramientas y productos útiles, como aprovechamiento y la explotación sostenible de la diversidad biológica en beneficio de la sociedad para mejorar la calidad de vida.

En esta búsqueda, uno de los mecanismos que se han encontrado, son los microorganismos llamados endófitos, los cuales son capaces de generar múltiples beneficios a las plantas superiores. En estudios se ha encontrado el uso de las bacterias para el crecimiento vegetal que logran mejorar la productividad y rendimiento de los cultivos aprovechando las propiedades antimicrobiana, antiséptica y antioxidante para la inhibición de microorganismos causantes de enfermedades en cultivos de interés agrícola.
Las bacterias endófitas asociadas a especies vegetales han sido reportadas como productores de una diversidad de compuesto bioactivos con múltiples usos farmacológicos. Dentro de estos productos se ha reportado la producción de compuesto volátil, los cuales una vez producidos dentro de las plantas por los endófitos benefician a estas previéndolas de defensas contra fitopatógenos (PEREZ et al., 2010). Nuevos estudios sobre microrganismos endófitos se han orientado sobre la producción de estos compuestos y su potencial uso en la biotecnología. Grupos de microorganismos que son de particular interés biotecnológico desde el punto de vista de la producción de compuesto volátiles, que por su capacidad de producir un amplio espectro de compuesto aromáticos, incluyendo a los volátiles los cuales poseen una poderosa propiedades para su uso en la agricultura e industria son ahora motivo de investigación por parte de microbiólogos a nivel mundial. (PEREZ et al., 2013).

\section{MATERIALES Y MÉTODOS}

Obtención de Fitopatógeno. B. glumae ATCC 4026-1, fue facilitada por la Federación Nacional de Arroceros -FEDEARROZ.

Obtención del material vegetal. Las muestras vegetales de Neem se recolectaron en la localidad el Callo de la Cruz, perteneciente al municipio de San marcos, departamento de Sucre. De cada sitio se tomaron muestras de tejido vegetal (hojas y semillas) de forma aleatoria de 10 plantas, para dicha colecta se verificó que las plantas en buen estado fitosanitario y sin ningún síntoma biótico o abiótico. El material vegetal fue depositadao en bolsas plásticas rotuladas con el sitio de muestreo y fecha de recolección. Todos los análisis microbiológicos de las muestras vegetales se realizaron en el laboratorio de investigaciones microbiológicas de la Universidad de Sucre.

Aislamiento de bacterias endófitas. Las bacterias endófitas fueron aisladas a partir del material vegetal de Neem, empleando la metodología descrita por PÉREZ et al., (2010), el cual consiste en varios lavados con hipoclorito de sodio $5 \%$, alcohol $70 \%$, Tween 80 , y una solución de tampón fosfato que protege el material vegetal de la rigurosa proceso de desinfección. Una vez desinfectado el material vegetal se procedió a tomar 10 $\mu \mathrm{l}$ de la solución del tejido macerado en agua destilada estéril y depositar sobre la superficie de agar cetrimida y agar King B, medios selectivos para especies del genero Pseudomonas spp. e incubados a $30{ }^{\circ} \mathrm{C}$ durante 48 horas. Una vez transcurrido este tiempo cada morfotipo bacteriano fue aislado y purificado en cultivos axénicos. 
Prueba de actividad antibacteriana de bacterias endófitas de Neem. Para seleccionar las bacterias endófitas con actividad inhibitoria contra $B$. glumae se realizó la prueba de antagonismo empleando el método de difusión sobre agar con discos de papel filtro Whatman de un grado. Para ello, se preparó una solución de los diferentes asilados de bacterias endófitas a una concentración $10^{8}$ UFC, donde se sumergieron los discos de papel filtros y fueron colocados en la parte central de la superficie de medio King B inoculado previamente con la bacteria fitopatógena. Las placas se incubaron a $28^{\circ} \mathrm{C}$ por 48 horas (CUELLAR y HUSSEIN 2009). Se utilizó como control positivo discos de papel filtro impregnados con ácido oxolínico. La selección se realizó de acuerdo al tamaño del halo de inhibición reflejado para cada aislado de bacterias endófitas y comparadas con el control positivo. (ROJAS et al., 2012).

Preparación del inóculo: se colocó a crecer la cepa bacteriana en medio King B por 24 horas, se inocularon 10 colonias de la bacteria en $250 \mathrm{~mL}$ de caldo King B y se incubó 8 horas a $30^{\circ} \mathrm{C}$ por $175 \mathrm{rpm}$. En un matraz de $250 \mathrm{~mL}$ se preparó $90 \mathrm{ml}$ de King $\mathrm{B}$ y se adicionó 10 $\mathrm{mL}$ del inóculo por 10 horas a $175 \mathrm{rpm}$ a $3^{\circ} \mathrm{C}$. Para el proceso de fermentación se utilizó el medio modificado número 3 con $10 \mathrm{~g}$ de peptona, $8,2 \mathrm{~mL}$ de glicerol, $1 \mathrm{~g}$ de $\mathrm{KH}_{2} \mathrm{PO}_{4}$ y $0,5 \mathrm{~g}$ de $\mathrm{Mg} \mathrm{SO}_{4} .7 \mathrm{H}_{2} \mathrm{O}$ por litro a $\mathrm{pH} 6,8$. Se sembró en el medio número 3 en relación 1:10 de inóculo y se incubó a temperatura ambiente durante 5 días a 150 rpm, en el transcurso de los días se midió el pH y absorbancia de la suspensión bacteriana para realizar la curva de crecimiento. Para la extracción de los metabolitos secundarios, se centrifugó el medio en tubos falcón de 50 $\mathrm{ml} \mathrm{a}$ 17,000 rpm dos veces durante 30 minutos. Luego se filtró el sobrenadante utilizando un filtro con tamaño de poro $0,2 \mu \mathrm{m}$. Se recolectó el filtrado para su utilización en ensayo de evaluación in vitro.

Método para determinar la actividad antimicrobiana de los extractos metabólicos. Una colonia pura de B. glumae fue transferida a $20 \mathrm{ml}$ de caldo King B en incubada a $30^{\circ} \mathrm{C}$ a $150 \mathrm{rpm}$ durante $24 \mathrm{~h}$, pasado este tiempo la suspensión bacteriana fue ajustada a una concentración de 0,5 Macfarland. Por otra parte las muestras de las suspensiones metabolicas tomadas a las diferentes horas (24, 48, 72 y $120 \mathrm{~h})$, se prepararon diluciones a las concentraciones $3,6,12,25$ a $50 \%$. La actividad bactericida de cada extracto fue evaluada por separado utilizando la técnica de Microdilución en placas de 96 pozos (CARVAJAL et al., 2013). A partir de la solución stock se realizaron 5 diluciones seriadas por triplicado en medio King B, en relación 1:1, para un volumen final de 90 $\mu \mathrm{L} /$ pozo de cada dilución, para obtener las concentraciones antes mencionadas posteriormente se añadió a cada pozo $10 \mu \mathrm{l}$ de la suspensión bacteriana para completar un volumen final de $100 \mathrm{~mL}$ por pozo. En cada placa se incluyeron controles de esterilidad del medio $(100 \mu \mathrm{l}$ de caldo King B), control de crecimiento (90 $\mu$ l medio King B+ $10 \mu \mathrm{l}$ de suspensión bacteriana) y control de los metabolitos $(100 \mu l)$, las placas se taparon y sellaron con crista Flex y se incubaron a $150 \mathrm{rpm}$ a $30^{\circ} \mathrm{C}$ durante 24 horas en incubadora Heidolph 1000 (modelo D-91126).

Transcurrido el tiempo de incubación, se adicionaron 15 $\mu \mathrm{L}$ de una solución acuosa $(0,5 \mathrm{mg} / \mathrm{ml})$ de MTT (bromuro de 3- [4,5-dimetiltiazol-2-il]-2,5-difenil tetrazolium) a los pozos que contenían los tratamientos y los controles. Después de una incubación por 45 minutos se descartó el contenido de los pozos y se adicionó $100 \mu \mathrm{L} /$ pozo de DMSO concentrado y se procedió a determinar la densidad óptica en un lector de Chromate Awareness, modelo 4300 utilizando una longitud de onda de $492 \mathrm{~nm}$. Con los resultados de las lecturas, se determinó el porcentaje de inhibición empleando la siguiente formula:

$\%$ IB $=1-\left(\right.$ Aai/Acc ${ }^{*} 100$

Dónde:

Aai: promedio de crecimiento de cada tratamiento

Acc: promedio de crecimiento prueba control.

Producción de sideróforos. El medio cromo azurol-S (CAS) fue preparado según Schwyny Neilands (1987) disolviendo $60,5 \mathrm{mg}$ de CAS en $50 \mathrm{ml}$ de agua destilada, y luego mezclada con $10 \mathrm{ml}$ de una solución de hierro (III) ( $1 \mathrm{mM}$ de $\mathrm{FeCl}_{3} .6 \mathrm{H}_{2} \mathrm{O}$ y $10 \mathrm{mM}$ de $\mathrm{HCl}$ ). Bajo agitación, esta solución de mezcla con 72,9 mg de HDTMA disuelto en $40 \mathrm{ml}$ de agua. El líquido azul resultante es autoclavado a $121^{\circ} \mathrm{C}$ por 15 minutos. Así, mismo, se autoclavo una mezcla de $750 \mathrm{ml}$ de agua, $15 \mathrm{~g}$ de agar; $30,24 \mathrm{~g}$ de pipes y $12 \mathrm{~g}$ de una solución $50 \%$ (w/w) de $\mathrm{NaOH}$ para alcanzar un $\mathrm{pH}$ de 6.8. Al medio se le agregaron $4 \mathrm{~g}$ de glucosa como fuente de carbono. Se tomó una colonia utilizando palitos de madera realizando puntos en el agar y se incubo durante 7 días a $30^{\circ} \mathrm{C}$. La habilidad de la bacteria para producir sideróforos se evidenció por la formación de un halo transparente alrededor de las colonias.

Identificación de la bacteria endófita con potencial inhibitorio contra $\boldsymbol{B}$. glumae. Se realizó la prueba de oxidasa, observación de la bacteria con tinción diferencial y siembra en medios selectivos agar MacConkey, Agar EMB y cetrimida. La identificación se llevó a cabo por medio el sistema miniaturizado API20 NE, y los resultados fueron analizados mediante el software digital facilitado por https:// apiweb.biomerieux.com

Análisis estadístico. La investigación se realizó bajo un diseño factorial $5 \times 3$ con un análisis de varianza de doble vía. Se determinaron dos factores experimentales: las concentraciones con 5 niveles 3, 6, 13, 25 y $50 \%$ y el tiempo de actividad del metabolito secundario bacteriano con tres niveles $(24,48$ y 72 h) y una variable respuesta que fue el porcentaje de inhibición sobre el crecimiento de la bacteria. 


\section{RESULTADOS}

La bacteria endófita seleccionada F3N4 obtenida de tejidos vegetales de Neem, corresponde a un bacilo gramnegativo, la cual se sembró en medio Cetrimida y King B e incuba a $37^{\circ} \mathrm{C}$ por $24 \mathrm{~h}$. Después de este tiempo se observó la presencia de colonias con pigmentación verdosa y fluorescencia en UV, colonias redondas, de borde liso, superficie lisa y actividad bioquímica de no fermentar lactosa. La identificación de la bacteria endófita con potencial inhibitorio contra $B$. glumae se realizó por medio un kit API 20 NE, permitiendo identificar con un porcentaje de similitud de un $99,5 \%$ a Ps. aeruginosa.

Al observar el comportamiento cinético en medio de cultivo inductor de la producción de metabólítos secundarios bacterianos tipo antibiótico (medio N3), se pudo establecer que a las condiciones de crecimiento establecidas ( $T$, rpm, Medio de cultivo, pH), la fase exponencial de la bacteria tiene una duración de ocho horas para entrar a fase estacionaria, momento en el cual, teóricamente la bacteria empieza a producir metabólítos secundarios. Por tanto, el tiempo en el que la bacteria demora en entrar en fase estacionaria fue de 11 horas contadas a partir de la inoculación en el medio Figura 1.

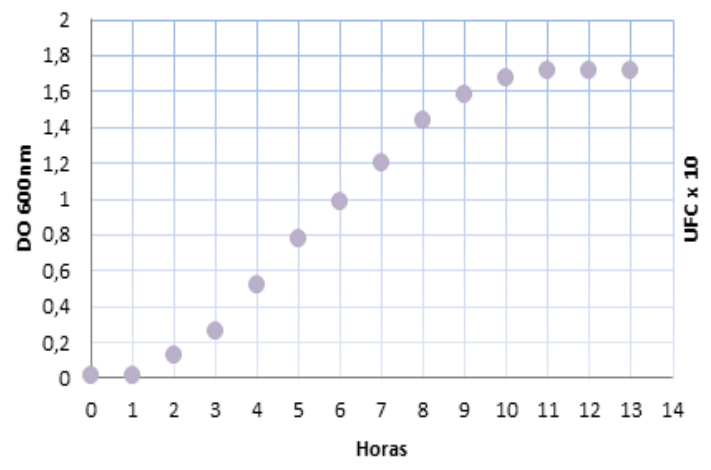

Figura 1. Curva de crecimiento de, bacteria endófita asilada de tejidos de Neem F3N4 identificada como Ps. aeruginosa

El medio N3 empleado, es un medio comercial utilizado para llevar a las bacterias a la producción de metabólítos tipo antibiótico. Para este ensayo se realizó una modificación a la fuente de carbono, determinando por ensayos que la bacteria endófita consumía rápidamente el glicerol, disminuyendo el tiempo para entrar a fase estacionaria.

Prueba de inhibición de suspensión metabólica de bacteria endófita contra B. glumae. Los mismos montajes empleados para la cinética de crecimiento en medio N3, fueron empleados para la obtención de metabolitos. Una de las inquietudes que se tenía con respecto a la producción de metabolitos con posible actividad inhibitoria, era en que tiempo de la fase estacionaria se producían los metabolitos. Debido a esto los resultados de la inhibición arrojaron que las muestras colectadas a las 24 horas de crecimiento bacteriano (tiempo en el que la bacteria tenía 13 horas en fase estacionaria) se obtuvieron los mayores valores de porcentajes de inhibición contra $B$. glumae, comparados con los resultados de inhibición de las muestras correspondientes a las 48 y 72 ( $P>$ valor: 0,0002) (Figura 3).

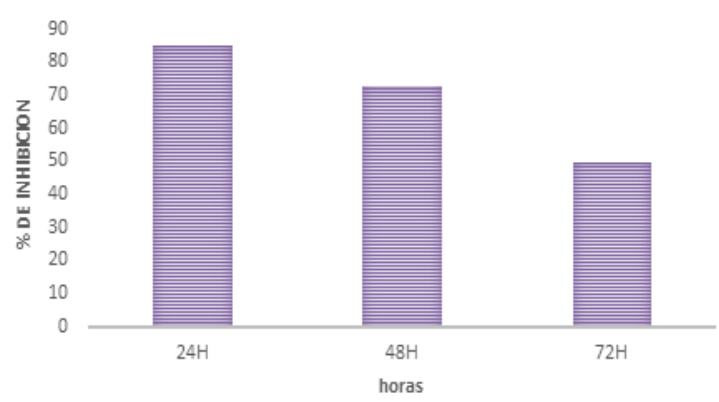

Figura 2: Porcentajes de inhibición de la bacteria endófita F3N4 contra B. glumae de las muestras colectadas a las 13 horas $(24 \mathrm{~h})$, 37 horas $(48 \mathrm{~h})$ y 61 horas $(72 \mathrm{H})$ de duración en fase estacionaria.

Adicionalmente, de las muestras tomadas a diferentes tiempos de la fase estacionaria, se realizaron diluciones obteniéndose para cada tiempo cinco concentraciones. Los resultados estadísticos arrojaron diferencias significativas entre las concentraciones de las muestras tomadas a 24,48 y $72 \mathrm{~h}$. Se observa que los mejores resultados de inhibición estuvieron en las concentraciones $50 \% \mathrm{v} / \mathrm{v}$. Asi que a esta concentración el porcentaje de inhibición para las muestras de 24, 48 y 72 horas fue 85,68 y $50,67 \%$ respectivamente (Figura 3 ), observándose una vez más que los valores de las concentraciones evaluadas con muestras recolectadas a las $24 \mathrm{~h}$ tienen mejor resultados de inhibición.

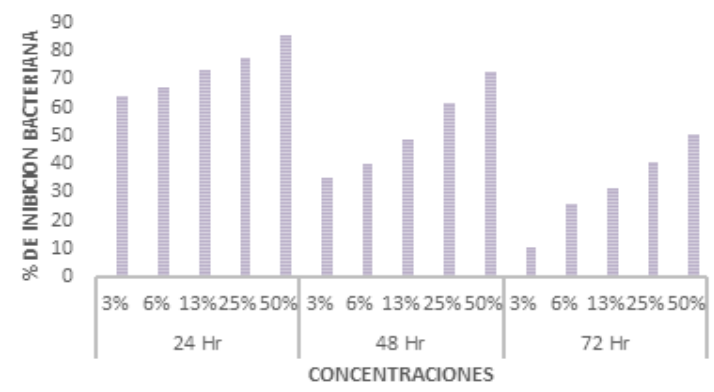

Figura 3. La gráfica muestra el porcentaje de inhibición de la bacteria endófita contra $B$. glumae a las concentraciones establecidas para las muestras de suspensión metabólica tomadas a las $24 \mathrm{~h}, 48 \mathrm{~h}$ y $72 \mathrm{~h}$ en fase estacionaria.

Una posible explicación del porque el descenso de la inhibición a mayor tiempo de incubación en fase estacionaria, se puede establecer con base a que la bacteria empezó una nueva fase exponencial 
pasadas las 48 horas de incubación; en este periodo se observó un nuevo crecimiento bacteriano (aumento de la OD), aumento de $\mathrm{pH}$ del medio (Tabla 1) y cambio de coloración en el medio (viraje de verde a café). Los datos de porcentaje de inhibición, los cambios en el $\mathrm{pH}$ y coloración pueden indicar una posible activación metabólica, a partir del consumo de productos sintetizados, muy probablemente en la fase estacionaria, lo cual reduciría la concentración del metabolito inhibidor en el tiempo y por ende el porcentaje de inhibición bacteriano.

Tabla 1. Valores de $\mathrm{pH}$, en los diferentes tiempos de muestreo en el proceso de producción de metabolitos de la bacteria endófita F3N4.

\begin{tabular}{cc}
\hline Tiempo & pH \\
\hline $24 \mathrm{~h}$ & 7,37 \\
$48 \mathrm{~h}$ & 8,7 \\
$72 \mathrm{~h}$ & 8,86 \\
$102 \mathrm{~h}$ & 8,96 \\
\hline
\end{tabular}

Producción de sideróforos de la bacteria endófita F3N4. La producción de sideróforos es una característica que presenta esta bacteria, la cual secreta pioverdina (fluoresceína), un sideróforo fluorescente de color amarillo verdoso cuya función es la de captar el hierro del medio necesario para el metabolismo del microorganismo y esto se da bajo condiciones limitadas de hierro. El obtener sideróforos mediante cultivo sumergido permite contar con un metabolito efectivo en el control de patógenos en plantas, La bacteria endófita F3N4, muestra una gran capacidad de producir sideróforos en medio de cultivo CAS, observado por la formación de un halo transparente alrededor de las colonias (Figura 4).

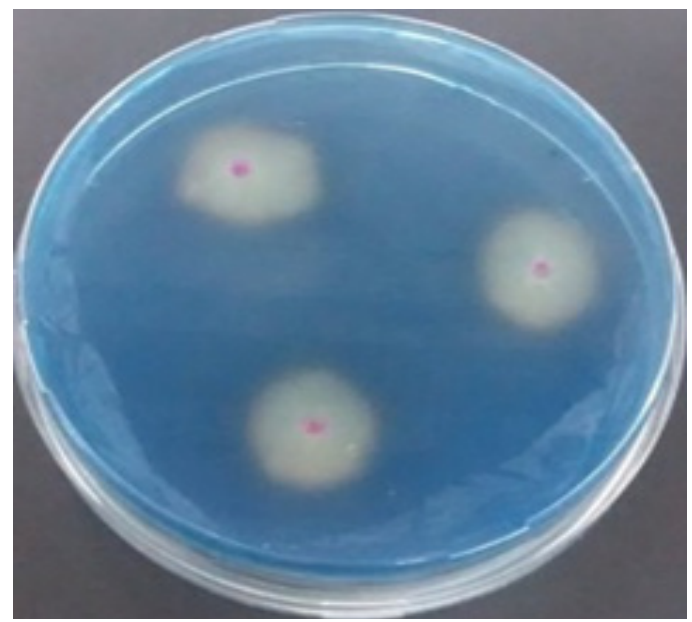

Figura 4. Habilidad de la bacteria endófita F3N4 in vitro para producir sideróforos. Fuente: Bravo, 2016

\section{DISCUSIÓN}

Actualmente la tendencia mundial es hacia la disminución del uso de plaguicidas químicos, en el control de plagas y enfermedades que atacan los cultivos agrícolas; por lo que se buscan métodos alternativos, entre los que se encuentran los biológicos, con el empleo de microorganismos y/o sus metabolitos para el tratamiento de enfermedades provocadas por fitopatógenos, con vistas a la protección ambiental y aumentar la productividad en la agricultura. Entre los microorganismos empleados en el control biológico, se destacan las especies del género Pseudomonas, por su gran versatilidad de producir metabolitos secundarios antimicrobianos, como: sideróforos y antibióticos, los cuales pertenecen a grupos de compuestos químicamente definidos y con funciones biológicas específicas, contra hongos fitopatógeno y bacterias patógenas. La inhibición del patógeno por la producción de metabolitos antimicrobianos o quelantes de hierro (sideróforos), son considerados como los principales mecanismos de biocontrol. La producción de metabolitos secundarios le ha permitido a las plantas protegerse del ataque de diversos microorganismos patógenos. (ROJAS et al., 2012). La Pseudomonas fluorescens ha sido utilizada como agente de biocontrol, producen diferentes metabolitos efectivos contra bacterias y hongos fitopatógenos, entre ellos sideróforos (ALANíS y GUERRERO 2007). La cepa de Pseudomona sp. PsJN una bacteria endófita identificada en plantas de cebolla, inhibe el crecimiento del hongo Botritis cinérea reduciendo su crecimiento para luego colonizar los tejidos de estas plantas (PÉREZ et al., 2013). Según ERNESTO, (2007) el género Pseudomona incluye un sin número de bacterias Gram negativas con gran versatilidad metabólica, por que presenta la capacidad de producir metabolitos secundarios útiles, los cuales actúan como agentes de control biológicos, evidenciado por los resultados encontrados en este estudio.

\section{CONCLUSIÓN}

La bacteria $P$ s. aeruginosa aislada a partir de Neem, se convierte en potencial biológico para el control in vitro de la bacteria B.glumae causante del añublo bacteriano de la panícula del arroz en el departamento de Sucre. Además, podría ser una alternativa para disminuir el uso continuo de fungicidas y se convierte a futuro en un recurso natural para reducir la contaminación del medio ambiente debido al uso indiscriminado de pesticida para el manejo de la enfermedad en campo. Así mismo, existe una diversidad incalculable de bacterias endófitas que presentan actividad antimicrobiana al menos sobre algún fitopatógeno, lo que representa la oportunidad de encontrar nuevos productos naturales que puedan ser utilizados como antibióticos eficaces en el futuro para el control y erradicación de enfermedades en cultivos de interés comercial en Colombia 


\section{Agradecimiento}

Los autores y la Universidad de Sucre expresan sus agradecimientos a la Gobernación del departamento de Sucre y al Fondo Nacional de Ciencias, Tecnología e Innovación (CTe I) del Sistema general de regalías-
SGR, por la realización de las actividades de Ciencia, Tecnología e Innovación en el marco del proyecto denominado "Implementación de un programa para el desarrollo de productos biotecnológicos para el sector agrícola en el Dpto de Sucre", Código BPIN 2013000100022, celebrado mediante Convenio Especial de Cooperación No 017 de 2014.

\section{REFERENCIA}

ÁLVAREZ, E.; OSPINA, C.; MEJIA, J.; LLANO, G. 2004. Caracterización morfológica, patogénica y genética del agente causal de la antracnosis (Colletotrichum gloesporioides) en guanábana (Annona muricata) en el Valle del Cauca. Fitopatología Colombiana. 28(1): 1-8.

ARAUJO, W.; MARCON, J.; MACCHERONI, W.; VAN ELSA, J.; VAN VUURDE, J.; AZEVEDO, J. 2002. Diversity on endophytic bacterial populations and their interaction with Xylella fastidiosus in Citrus plants. Applied Environmental Microbiology. 68:4906-4914.

CHANWAY, C. 1998. Bacterial endophytes: ecological and practical implications. Sydowia.50:149-170.

CHO, S.; LEE S-K.; CHA, BJ:, KIM, YH.; SHIN, K-S. 2003. Detection and characterization of the Gloeosporium gloeosporioides growth inhibitory compound iturin A from Bacillus subtilis strain KS03. FEMS Microbiology Letters. 223: 47-51.

CUELLAR, A.; HUSSEIN, R. 2009. Evaluation of the yield and the antimicrobial activity of the essential oils from: Eucalyptus globulus, Cymbopogon citratus and Rosmarinus officinalis in mbarara district (Uganda). Revista Colombiana de Ciencia Animal. 1(2): 240-249.

ESTRADA, P.; MAVINGUI, P.; COURNOYER, B.; FONTAINE, F.; BALANDREAU, J.; CABALLERO, J. 2002. A N2fixing endophytic Burkholderia sp associated with maize plants cultivated in Mexico. Canadian Journal of Microbiology. 48: 285-294.

FÖLDES, T.; BÀNHEGYI, I.; HERPAI, Z.; VARGA, L.; SZIGETI, J. 2000. Isolation of Bacillus strains from the rhizosphere of cereals and in vitro screening for antagonism against phytopathogenic, food-borne pathogenic and spoilage microorganisms. Journal of Applied Microbiology. 89: 840-846.

FORCHETTI, G.; MASCIARELLI, O.; ALEMANO, S.; ÁlVAREZ, D.; ABDALA, G. 2007. Endophytic bacteria in sunflower (Helianthus annuus L.): isolation, characterization, and production of jasmonates and abscisic acid in culture medium. Applied Microbiology and Biotechnology. 76: 1145-1152.

FREEMAN, S.; KATAN, T.; SHABI, E. 1998. Characterization of Colletotrichum species responsible for Anthracnose diseases of various fruits. Plant Disease. 82(6): 596- 605.

GREEN, K.; ABANG, M.; LLOBA, C. 2000. A rapid Bioassay for Screening Yam Germplasm for Response to Anthracnose. Tropical Science. 40:132-8.

HASSAN, S.; HAQ, A.; BYRD, J.; BERHOW, M.; CARTWRIGHT, A.; BAILEY, C. 2010. Haemolytic and antimicrobial activities of saponin-rich extracts from guar meal. Food Chemistry. 119: 600-605.

IWAI, T.; KAKU, K.; HONKURA R.; NAKAMURA S.; OCHIAH, T.; SASAKI, E.; OHASHI, Y. 2002. Enhanced resistance to seed transmitted bacterial diseases in transgenic rice plants overproducing an oat cell wall bound thionin. Mol. Plant Microbe Interact. 15(6): 515 - 521. 
JAMES, E. 2000. Nitrogen fixation in endophytic and associative symbiosis. Field. Crops Research. 65:197-209.

JIMÉNEZ-SALGADO, T.; FUENTES-RAMÍREZ, L.; TAPIA-HERNÁNDEZ, A.; MASCARUA-ESPARZA, M.; MARTÍNEZ-ROMERO, E.; CABALLERO-MELLADO, J. 1997. Coffeaarabical a new host plant for Acetobacter diazotrophicus, and isolation of other nitrogen-fixing acetobacteria. Applied Environmental Microbiology. 63:3676-3683.

MENDES, R.; PIZZIRANI, A.; WELINGTON, L.; RAAIJMAKERS, J. 2007. Diversity of Cultivated Endophytic Bacteria from Sugarcane: Genetic and Biochemical Characterization of Burkholderia cepacia Complex Isolates. Applied Environmental Microbiology. 66 (22): 7259-7267.

MUNIMBAZI, C.; BULLERMAN, LB. 1998. Isolation and partial characterization of antifungal metabolites of Bacillus pumilus. Journal of Applied Microbiology. 84: 959-968.

MUÑOZ, R.; CABALLERO, M. 2003. Population dynamics of Gluconacetobacter diazotrophicus in sugarcane cultivars and its effect on plant growth. Microbial Ecology. 46: 454-464.

NEWMAN, L.; REYNOLDS, C. 2005. Bacteria and phytoremediation: new uses for endophytic bacteria in plants. Trends in Biotechnology. 23(1): 6-8.

PALANIYANDI, S.; YANG, S.; CHENG, J.; MEENG, L...; SUH, J. 2011. Biological control of anthracnose (Colletotrichum gloeosporioides) in yam by Streptomyces sp. MJM5763. Journal of applied microbiology. 111(2): 443-455.

PÉREZ, A.; ROJAS, J.; ANAYA, L.; PÉREZ, K. 2011. Evaluación in vitro de actividad inhibitoria de extractos vegetales sobre cepas de hongos del género Colletotrichum sp. Revista Acta Agronómica. 60(2): 158-164.

PÉREZ, C.; ROJAS, J.; FUENTES, J. 2010. Diversidad de bacterias endófitas asociadas a raíces del pasto colosuana (Bothriochloa pertusa) en tres localidades del departamento de Sucre, Colombia. Revista Colombiana de Biotecnología. XIV (1): 224-232.

PILLAY, V.; NORWARK, J. 1997. Inoculam, density, temperature, and genetype effect on in vitro growth promotion and epiphytec and endophytec colonization of tomato (Lycopersicon esculentum L.), seeding inoculated with a Pseudomonal bacterium. Canadian Journal of Microbiology. 43: 354-361.

PROGRAMA DE LAS NACIONES UNIDAS PARA EL MEDIO AMBIENTE. Oficina Regional para América Latina y el Caribe. Decenio de las Naciones Unidas sobre la Biodiversidad 2011-2020. [Online]. Ciudad de Panamá, Panamá. Recuperado el 15 de Abril de 2016, de http://www.pnuma.org/biodiversidad/index.php.

REINA, Y. 2012. El Cultivo del Ñame en el Caribe Colombiano. Banco de la República. Centro de Estudios Económicos Regionales (CEER)-Cartagena. Documento de Trabajo sobre Economía Regional. 168: 1-34.

ROJAS, J.; PÉREZ, A, MARTíNEZ, JOSÉ.; JORGE, MIELES. 2012. Actividad antibacteriana de extracto de hojas de Melia azedarach L. Revista Colombiana. Biotecnología. XIV (1):224-232.

ROSENBLUETH, M.; MARTINEZ, E. 2006. Bacterial endophytes and their Interactions with hosts. Molecular Microbes-Plant Interactions. 19(8):827-837.

RUSH, M.; Q.; SHAO, S.; ZHANG, K.; SHAHJAHAN, K.; O’REILLY, D.; SHIH, D.; GROTH, D. LINSCOMBE. 2003. Biotechnology and control of rice diseases. Biological control of rice diseases. In: S.S. Gnanamanickam (ed.) Biological Control of Crop Diseases. Marcel Dekker Inc. New York, 468p

SALDARRIAGA-CARDONA, A.; CASTAÑO-ZAPATA, J.; ARANGO-ISAZA, R. 2008. Caracterización del agente causante de la antracnosis en tomate de árbol, manzano y mora. Revista Académica Colombiana de Ciencia. 32 (123): 145-156.

SECRETARIA DE DESARROLLO ECONÓMICO Y MEDIO AMBIENTE DE SUCRE. Gobernación de Sucre. Ministerio de Agricultura y Desarrollo Rural. Informe de Coyuntura. Sincelejo. 2008. 
SESSITSCH, A.; HOWIESON, J.G.; PERRET, X.; ANTOUN, H.; MARTINEZ-ROMERO, E. 2002. Advances in Rhizobium research. Journal Critical Reviews in Plant Sciences. 21:323-378.

SHULZ, B.; BOYLE, C. 2006. What are endophytes Microbial root endophytes? Berlin Heidelberg. Soil Biology. 9:1-13.

TSAVKELOVA, E.; CHERDYNTSEVA, T.; BOTINA, S.; NETRUSOV, A. 2007. Bacteria associated with orchid roots and microbial production of auxin. Microbiological Research. 162: 69-76.

UEMATSY, T.; YOSHIMURA, D; NISHIYAMA, K.; IBARAGI, T.; FUJII, H. 1976. Pathogenic bacterium causing seedling rot of rice. Ann. Phytopathol. Soc. Jpn. 42:464-471.

WANG, E.; TAN, Z.; GUO, X.; DURAN, R.; BOLL, G; MARTINEZ, E. 2006. Diverse endophytic bacteria isolated from a leguminous tree Conzattia multiflora grown in Mexico. Archives of Microbiology. 186:251-259.

WULFF, EG.; MGUNI, CM.; MANSFELD, K.; FELS, J.; LÜBECK, M.; HOCKENHULL, J. 2002. Biochemical and molecular characterization of Bacillus amyloliquefaciens, $B$. subtilis and $B$. pumilus isolates with distinct antagonistic potential against Xanthomonas campestris pv. campestris. Plant Pathology. 51: 574-584.

ZHANYONG, G.; RONGE, X.; SONG, L.; ZHIMEI, Z.; XIA, J., LIN, W.; PENGCHENG, L. 2008. The Influence of Molecular Weight of Quaternized Chitosan on Antifungal Activity. Journal Carbohydrates and Polymers. 71(4): 694-69 